\title{
The association between chronic bullying victimization with weight status and body self-image: a cross-national study in 39 countries
}

\author{
Qiguo Lian ${ }^{1,2}$, Qiru Su ${ }^{3}$ ， Ruili Li ${ }^{4}$, Frank J Elgar ${ }^{5}$, Zhihao Liu ${ }^{6}$, Dongpeng Zheng ${ }^{\text {Corresp. }} 7$ \\ ${ }^{1}$ Key Lab. of Reproduction Regulation of NPFPC, SIPPR, IRD, Fudan University, Shanghai, China \\ 2 School of Public Health, Fudan University, Shanghai, China \\ 3 National Immunization Program, Chinese Center for Disease Control and Prevention, Beijing, China \\ ${ }^{4}$ Children Health and Development Department, Capital Institute of Paediatrics, Beijing, China \\ 5 Institute for Health and Social Policy, McGill University, Montreal, Canada \\ 6 Institute for Health Education, Jiangsu Provincial Center for Disease Control and Prevention, Jiangsu, China \\ 7 Huajing Community Health Service Center, Shanghai, China \\ Corresponding Author: Dongpeng Zheng \\ Email address: Dongpeng.Zheng@huajing.org.cn
}

Background: Childhood obesity and school bullying are pervasive public health issues and known to cooccur in adolescents. However, the association between underweight or thinness and chronic bullying victimization is unclear. The current study examined whether chronic bullying victimization is associated with weight status and body self-image.

Methods: A school-based, cross-sectional study in 39 North American and European countries and regions was conducted. A total of 213,595 adolescents aged 11, 13, and 15 years were surveyed in 2009/10. Chronic bullying victimization was identified using the Revised Olweus Bully/Victim Questionnaire. Weight status was determined using self-reported height and weight and the body mass index (BMI), and body self-image was based on perceived weight. We tested associations between underweight and bullying victimization using three-level logistic regression models.

Results: Of the 213,595 adolescents investigated, $11.28 \%$ adolescents reported chronic bullying victimization, $14.80 \%$ were classified as overweight/obese according to age- and sex-specific BMI criteria, $12.97 \%$ were underweight, and $28.36 \%$ considered themselves a little bit fat or too fat, $14.57 \%$ were too thin. Bullying victimization was less common in older adolescent boys and girls. Weight status was associated with chronic bullying victimization (adjusted $\mathrm{OR}_{\text {underweight }}=1.10,95 \% \mathrm{Cl}=1.05-1.16, \mathrm{p}=0.002$; adjusted $\mathrm{OR}_{\text {overweight }}=1.40,95 \% \mathrm{Cl}=1.32-1.49, \mathrm{p}<0.0001$; adjusted $\mathrm{OR}_{\text {obese }}=1.91,95 \% \mathrm{Cl}=1.71-2.14$, $\mathrm{p}<0.0001$ ). Body self-image also related to chronic bullying victimization (adjusted $\mathrm{OR}_{\text {too thin }}=1.42,95 \%$ $\mathrm{Cl}=1.36-1.49, \mathrm{p}<0.0001$; adjusted $\mathrm{OR}_{\mathrm{a}}$ little bit fat $=1.54,95 \% \mathrm{Cl}=1.48-1.61, \mathrm{p}<0.0001$; adjusted $\mathrm{OR}_{\text {too fat }}$ $=3.30,95 \% \mathrm{Cl}=2.96-3.68, \mathrm{p}<0.0001)$.

Conclusions: Both perceived weight and self-rated overweight are associated with chronic bullying victimization. Both overweight and underweight children are at risk of being chronically bullied. 
1 The association between chronic bullying victimization with weight status and body self2 image: a cross-national study in 39 countries

3

4 Qiguo Lian ${ }^{1,2} \mathrm{MD}$, Qiru Su ${ }^{3} \mathrm{MD}$, Ruili Li ${ }^{4} \mathrm{MD}$, Frank J Elgar ${ }^{5}$ Ph.D., Zhihao Liu ${ }^{6} \mathrm{MD}$, 5 Dongpeng Zheng ${ }^{7} \mathrm{MD}$

6

$7{ }^{1}$ Key Lab. of Reproduction Regulation of NPFPC, SIPPR, IRD, Fudan University, Shanghai, 8 China

$9 \quad 2$ School of Public Health, Fudan University, Shanghai, China

$10{ }^{3}$ National Immunization Program, Chinese Center for Disease Control and Prevention, Beijing, 11 China

$12{ }^{4}$ Children Health and Development Department, Capital Institute of Paediatrics, Beijing, China

$13 \quad{ }^{5}$ Institute for Health and Social Policy, McGill University, Montreal, Canada

$14{ }^{6}$ Institute for Health Education, Jiangsu Provincial Center for Disease Control and Prevention, 15 Jiangsu, China

$16{ }^{7}$ Huajing Community Health Service Center, Xuhui District, Shanghai, China

17 Correspondence Author:

18 Dongpeng Zheng

19 Huajing Community Health Service Center

20180 Jianhua Road, Xuhui District, Shanghai, China, 200231

21 Email: Dongpeng.Zheng@huajing.org.cn

22 Telephone: 8621-6496-0088 


\section{Abstract}

Background: Childhood obesity and school bullying are pervasive public health issues and known

to co-occur in adolescents. However, the association between underweight or thinness and chronic bullying victimization is unclear. The current study examined whether chronic bullying victimization is associated with weight status and body self-image.

Methods: A school-based, cross-sectional study in 39 North American and European countries and regions was conducted. A total of 213,595 adolescents aged 11, 13, and 15 years were surveyed in 2009/10. Chronic bullying victimization was identified using the Revised Olweus Bully/Victim

Questionnaire. Weight status was determined using self-reported height and weight and the body mass index (BMI), and body self-image was based on perceived weight. We tested associations between underweight and bullying victimization using three-level logistic regression models.

Results: Of the 213,595 adolescents investigated, 11.28\% adolescents reported chronic bullying victimization, $14.80 \%$ were classified as overweight/obese according to age- and sex-specific BMI criteria, $12.97 \%$ were underweight, and $28.36 \%$ considered themselves a little bit fat or too fat, $14.57 \%$ were too thin. Bullying victimization was less common in older adolescent boys and girls. $95 \% \mathrm{CI}=1.05-1.16, \mathrm{p}=0.002$; adjusted $\mathrm{OR}_{\text {overweight }}=1.40,95 \% \mathrm{CI}=1.32-1.49, \mathrm{p}<0.0001$; adjusted $\left.\mathrm{OR}_{\text {obese }}=1.91,95 \% \mathrm{CI}=1.71-2.14, \mathrm{p}<0.0001\right)$. Body self-image also related to chronic bullying

41 victimization (adjusted $\mathrm{OR}_{\text {too thin }}=1.42,95 \% \mathrm{CI}=1.36-1.49, \mathrm{p}<0.0001$; adjusted $\mathrm{OR}_{\mathrm{a} \text { little bit fat }}=1.54$, $4295 \% \mathrm{CI}=1.48-1.61, \mathrm{p}<0.0001$; adjusted $\left.\mathrm{OR}_{\text {too fat }}=3.30,95 \% \mathrm{CI}=2.96-3.68, \mathrm{p}<0.0001\right)$. 
43 Conclusions: Both perceived weight and self-rated overweight are associated with chronic

44 bullying victimization. Both overweight and underweight children are at risk of being chronically

45 bullied.

46 
47

48

49

50

51

52

53

54

55

56

57

\section{Introduction}

School bullying is widely considered to be a public health concern for children and adolescents.

Bullying victimization has been found to be a common adverse life event in young people worldwide (Anthony et al. 2010; Bowes et al. 2013). According to Dan Olweus, bullying is defined as intentional harmful behavior, carried out repeatedly, against an individual who is unable to defend themselves(Olweus 2013). Based on this definition, the Health Behavior in School-aged Children (HBSC) study found that $45.2 \%$ of boys and $35.8 \%$ of girls in 40 countries were exposed to bullying(Craig et al. 2009).

The predictors of bullying victimization include individual, family and school factors(Jeong et al. 2013). Children who are overweight/obese, with low self-esteem, come from low socioeconomic households, have few friends and experienced child abuse are more likely to be bullied (Fanti \& Henrich 2015; Shetgiri 2013; Tippett \& Wolke 2014). Some personal characteristics including internalizing problems (depression, anxiety) could increase the risk for victimization(Shetgiri 2013). Living in a two-parent family with high parental support and positive adult role models can protect against bullying perpetration(Tippett \& Wolke 2014). Besides, a positive school climate including adult support and peer support in school predicts within-class reduction of bullying(Gage et al. 2014).

The published evidence shows short- and long-term adverse consequences for the victims of school bullying. Compared to their peers, victims are at higher risk of a wide range of harmful effects, such as loneliness, anxiety, depression and low self-esteem (Ranta et al. 2009; Stapinski et al. 2015). There is an increasing concern about chronic school bullying. Children who suffered more 
frequent bullying by peers tend to display worse outcomes. These chronic victims tend to experience more psychotic symptoms later in life as well as more anxiety problems such as agoraphobia, panic disorder, and generalized anxiety(Kochenderfer \& Ladd 1996). Compared to occasional victims and non-bullied children, victims of chronic bullying are at elevated risk for maladjustment, which may lead them to bully others or to self-harm(Bowes et al. 2013). Moreover, school bullying can increase the risk for unhealthy behaviors that may lead to weight gain (e.g., increased caloric intake, binge eating, and increased sedentary activities) for individuals who are targeted(Puhl \& Luedicke 2012).

Childhood obesity also relates to various chronic health and social problems, including bullying victimization(Puhl \& Luedicke 2012). Up to $29 \%$ of children experienced bullying linked to their weight status(Puhl \& Luedicke 2012). Being overweight or obese is the primary reason that children are bullied at school(Puhl et al. 2011). The evidence shows a positive association between adiposity level and school bullying; that is, in general, children with overweight or obesity are more likely to be victims of bullying than their normal-weight peers(Bacchini et al. 2015; Lumeng et al. 2010) .Underweight children were also found to be at increased risk of being bullied occasionally(Wang et al. 2010), however the association between underweight and chronic bullying is still unclear. Aside from weight status, studies also found that self-image, independently of weight status, is associated with peer victimization (Reulbach et al. 2013; Sutter et al. 2015; Zequinão et al. 2017) . According to Reulbach et al., bullying perpetration was not associated with body mass index (BMI) derived weight status but associated with perceived selfdescription of weight(Reulbach et al. 2013). In another study, however, BMI z-score and body 
dissatisfaction are both significant predictors of bullying victimization(Sutter et al. 2015).

Against this background, the present study examined the association between chronic bullying victimization and adolescent's weight status, as determined using the body BMI z-scores, and with body self-image, a subjective indicator of weight status. Also, we computed predicted probabilities of chronic bullying victimization based on weight status and body-image. We hypothesized that the probability of chronic bullying victimization would be lowest in normal weight status group for both BMI and body-image indicators. Specifically, based on literature(Sutter et al. 2015; Zequinão et al. 2017), we assumed that weight status and body-image are independent predictors to chronic bullying victimization, and the associations of victimization with weight status and body-image are consistent across countries.

\section{Materials \& Methods}

\section{Study design and participants}

Data for this study were drawn from the 2009/10 HBSC study, a school-based cross-sectional survey conducted in 39 North American and European countries and regions every four years (Chester et al. 2015; Elgar et al. 2015). The study recruited an international sample $(\mathrm{N}=213,595)$ of schoolchildren aged 11,13 and 15 years using identical sampling methods, which is much larger than required sample size for statistical power 0.8 estimated by retrospective power analysis. The sampling unit was a classroom within schools selected by inverse probability weighting to guarantee that students were equally likely to be sampled. The desired sample size for each age group was 1,500 (750 boys, 750 girls) per country/region. Students anonymously completed the self-administered questionnaires in classroom settings and handed them to teachers or well-trained 
110 assistants.

111 The study was reviewed and approved by university-based or equivalent review boards. Parental

112 consent procedures depend on school district policy. Once obtained parental consent, students

113 provided their assent to participate.

114 Measures

115 Outcome

116 Chronic bullying victimization

117 We measured the experiences of bullying victimization using the question: "How often have you

118 been bullied at school in the past couple of months" with options $0=\mathrm{I}$ haven't been bullied, $1=$ Once

119 or twice, $2=2$ or 3 times a month, $3=$ About once a week, $4=$ Several times a week. We recoded

120 items 1 and 2 as non-chronic bullying victimization, items 3 to 5 as chronic bullying victimization.

121 Before the question, there was a definitional statement of bullying adapted from the Revised

122 Olweus Bully/Victim Questionnaire to ensure consistency in responses(Olweus 1994) .

123

124

125

126

127

\section{Exposures}

\section{Perceived weight status}

We calculated body mass index $\left(\mathrm{BMI} ; \mathrm{kg} / \mathrm{m}^{2}\right)$ based on self-reported weight and height, converted the BMI values to exact z-scores, then divided the adolescents into four categories (underweight, normal weight, overweight and obese) according to age- and sex-specific z-scores cut-off points, as recommended by the International Obesity Task Force(Cole et al. 2000; Cole et al. 2007) . 
129 Although self-reported weight and height are vulnerable to reporting bias, several studies revealed

130 high correlations between reported and measured BMI in adolescents(Haines et al. 2008; Himes

131 et al. 2005; Paxton et al. 2004).

132

133

134

135

136

137

138

139

140

141

142

143

144

145

146

147 148 (range 0-9).

\section{Confounders}

\section{Perceived body-image}

To assess body self-image, we asked the participants whether they perceived their body as "Much too thin," "A bit too thin," "About right," "A bit too fat," or "Much too fat." For consistency with the classification of weight status, we combined the replies of the first two options ("much too thin" and "a bit too thin") into "too thin."

\section{Socioeconomic status}

We measured socioeconomic status (SES) of the respondents using the Family Affluence Scale (FAS). The scale is developed by HBSC Methodology Development Group, and comprised of four items: "Does your family own a car, van or trunk?" $\left(\mathrm{No}_{=}=0, \mathrm{Yes}=1, \mathrm{Yes}\right.$, two or more=2); "Do you have your own bedroom?" $(\mathrm{No}=0, \mathrm{Yes}=1)$; "During the past 12 months, how many times did you travel away on holiday (vacation) with your family?" (Not at all=0, Once=1, Twice=2, More than twice=3); and "How many computers does your family own?" (None=0, One $=1$, Two $=2$ More than $\mathrm{two}=3$ ). The FAS has been validated as a better proxy of parental SES and is less affected by nonresponse bias than other measures(Currie et al. 2008). We divided the respondents into high (6-9), medium (3-5) and low (0-2) groups according to the total score 


\section{Family structure}

150 We recorded family structure as "traditional" if the participants lived with 'both biological

151 parents', and "non-traditional" if they lived with a 'single mother,' 'single father,' in a

152 'reconstituted family' or 'other.'

153

154

155

\section{Classmate support}

We measured the perceived classmate support using a subscale of three items: "Students in my class(es) enjoy being together," "Most of the students in my class(es) are kind and helpful" and “Other students accept me as I am.” Participants responded on a Likert scale of five points, from "Strongly agree" to "Strongly disagree." In this paper, students who agreed or strongly agreed with all the three statements were classified as having positive classmate relationships.

\section{Country-level data}

We also collected the country-level data, including GDP per capita and Gini coefficient, on these 39 countries/regions (table 1 ).

\section{Statistical analysis}

We analyzed the data using Stata/SE 14.0. The prevalence estimates were presented separately for each gender. Given these data were hierarchical, with individuals nested within schools, and schools nested within countries, we tested associations of school bullying victimization between weight status and body self-image separately for males and females using three-level logistic regression models with adjustment for potential confounding by age, classmate support, family 
168 structure, and FAS group. We weighted the data to adjust the clustered sampling design of the 169 survey. Odds ratios (ORs) and 95\% confidential intervals (CIs) were used to measure the 170 association.

171 After fitting the logistic models, we computed and plotted the adjusted predicted probability of 172 being chronic bullying victims for weight status and body self-image by variables value using Stata

173

174

175

176

177

178

179

180

181

182

183

184

185

186

187

margins and marginsplot commands. Similarly, we estimated the average marginal effects of weight status and body self-image.

\section{Results}

A total of 213,595 adolescents from 7,468 schools in 39 countries and regions were investigated, of which 105,099 were boys, and 108,496 were girls, accounting for $49.20 \%$ and $50.80 \%$, respectively (table 1). In our sample, 22,822 (11.28\%) adolescents were identified as having been exposed to chronic bullying victimization. Also, $12.79 \%, 12.19 \%$ and $2.61 \%$ of the participants were classified as underweight, overweight and obese according to age- and sex-specific BMI criteria, while $14.57 \%, 24.85 \%$ and $3.51 \%$ of the participants considered themselves too thin, a little bit fat and too fat. The Gini coefficient in 2010 ranged from 24.82 to 44.05 , with a mean of 31.94. The GDP per capita in 2010 ranged from 2,974 USD to 103,267 USD, and the average value was 35,052 USD.

As illustrated in table 2 and figure 1, we noted that the prevalence of chronic bullying victimization declined in older age groups, and this pattern remained consistent among boys and girls. The prevalence of chronic bullying victimization was lowest among normal weight/about-right 
populations and highest among obese/too-fat populations in both sex groups.

Next, we examined the associations between chronic bullying victimization with perceived weight and perceived body-image respectively. The associations of individual-level confounders with exposures and outcome were showed in table s1-s3 the Appendix. We controlled potential confounders at the individual level (sex, age group, SES, classmate support and academic achievement) and the macro level (country wealth and income inequality) and accounted for the multilevel structure of the data. We found that weight status was associated with chronic bullying victimization (adjusted $\mathrm{OR}_{\text {underweight }}=1.10, \mathrm{p}=0.002$; adjusted $\mathrm{OR}_{\text {overweight }}=1.40, \mathrm{p}<0.0001$; adjusted $\mathrm{OR}_{\text {obese }}=1.91, \mathrm{p}<0.0001$ ) (table 3 ). The association between body self-image with chronic bullying victimization was similar (adjusted $\mathrm{OR}_{\text {too thin }}=1.42, \mathrm{p}<0.0001$; adjusted $\mathrm{OR}_{\mathrm{a}}$ little bit fat $=1.54$, $\mathrm{p}<0.0001$; adjusted $\mathrm{OR}_{\text {too fat }}=3.30, \mathrm{p}<0.0001$ ) (table 4). We also performed gender-specific analyses that revealed there were no gender differences in obesity-related or fat-related chronic bullying victimization (table 3-4). We examined the interactions between weight status, bodyimage, and victimization, and did not observe positive results (table s4 in the Appendix).

We also computed the post-estimation predictions after fitting logistic models. As shown in figure 2 and table s5 in the Appendix, the estimated probabilities for weight status is 0.108 for underweight, 0.100 for normal weight, 0.131 for overweight and 0.166 for obese, the estimated probabilities were all higher in males than in females. On average, being underweight compared with being normal weight increased the probability of chronic bullying victimization by 0.031 $(\mathrm{p}<0.0001)$. Being overweight compared with being normal weight increased the probability by $0.032(\mathrm{p}<0.0001)$. Being obese compared with being normal weight increased the probability 
by $0.067(\mathrm{p}<0.0001)$. The estimated probabilities for body self-image were also calculated and

210 displayed in figure 2, and table s6 in the Appendix.

\section{Discussion}

212 This study involving 39 national representative samples of schoolchildren aged 11, 13 and 15 years using identical sampling methods, revealed that both overweight/obese and self-rated overweight were linked to increased risk of being chronic bullied. Furthermore, the study showed adolescents with underweight also had a higher risk of being chronically bullied than normal-weight adolescents, as their overweight/obese peers did. The link between underweight and chronic bullying victimization is a valuable addition to the scientific literature on occasional bullying, which suggests that vulnerable populations include not only adolescents with overweight/obesity(Puhl \& Luedicke 2012; Puhl et al. 2011) but also underweight adolescents.

To our knowledge, few studies have tested the association of chronic bullying victimization with both weight status and body self-image using cross-national data. Previous research found that for overweight and obese youth, weight stigmatization translates into pervasive victimization, teasing, and bullying(Puhl \& King 2013). While the weight-related bullying may be intuitive, the association between underweight and school bullying may be less clear, although there is a relationship between media influence and drive for thinness(Fernandez \& Pritchard 2012). Using the data from a large cross-national epidemiological sample, our results not only provide supporting evidence for the relationship between chronic bullying and overweight/obesity but also reveal the relationship between chronic bullying and underweight, for both boys and girls. 
were $1.91,1.40$ and 1.10 for obesity, overweight and underweight, respectively. The marginal

predicted probabilities of being chronically bullied were 0.17 for obesity, 0.13 for overweight,

0.11 for underweight, and 0.10 for normal weight. The strength of association between chronic

bullying and underweight was relatively weaker but still significant.

School bullying focuses on differences, and the differences can be either real or perceived. We

found similar but stronger relationships between chronic bullying and perceived body self-image.

Our finding echoes earlier research indicating BMI z-score and physical appearance independently

predicted the victimization (Bacchini et al. 2017). The research also found that self-concept

mediated the relationship between BMI z-score and bullying victimization (Bacchini et al. 2017),

however, we didn't observe the interactions between perceived weight status and body self-image

and further research is needed.

In adolescence, especially in females, being taunted about being overweight or obese may

contribute to the development of eating disorders such as anorexia nervosa, and internalizing

problems such as suicidal thoughts and depression(Lian et al. 2017). Significant residual obesity

stigma remains against individuals who have lost weight(Latner et al. 2012). Furthermore, our

results also indicate that adolescents with "too thin" body self-image are still vulnerable to chronic

bullying(Wang et al. 2010). These findings further our understanding of the weight-related

bullying and can help develop targeted preventative strategies to stop or lessen school bullying.

Programs for bullying prevention should not overlook psychosocial and cultural interventions,

which can help adolescents cope with their weight status better (Wilson et al. 2013).

250 Our study focuses on a particularly vulnerable group of bullied children: those who experienced 
251

chronic bullying victimization in school. In our sample from 39 countries, $11.28 \%$ of the children suffered chronic bullying, while the prevalence rose to $24 \%$ in a long-term study followed children from kindergarten through Grade 12 in the U.S. (Ladd et al. 2017). This inconsistency in prevalence is partly due to an age difference between samples(Ladd et al. 2017), the age-range was narrow in our study but broad in the U.S. study.

On average, the current study revealed an apparent gradual decline in reported chronic bullying with older age groups, for both boys and girls. The trend is observable in other large studies (Ladd et al. 2017; Olweus 1994; Rigby \& Smith 2011; Wang et al. 2009). Bullying is more frequent in early grade school, rather than in middle school and high school as popular media depicted(Ladd et al. 2017). This age-related decline in school bullying could be explained in part by two hypotheses: 1) the number of older pupils with opportunities to bully decreases with age; 2) potential victims (usually younger students) are getting more socially skilled.(Smith et al. 1999) The hypotheses indicate that modified playgrounds with increased opportunities for risk and challenge(Farmer et al. 2017), and early skill training when younger students start school (Smith et al. 1999) could help lessen school bullying.

\section{Strengths and Limitations}

Strengths of the current study include a sizeable cross-national sample, standardized questionnaire, and the ability to perform subgroup analyses on the effects of chronic bullying on groups of underweight and too thin individuals. This study uniquely examined the associations between chronic bullying victimization and weight status defined by BMI and body-image. An important limitation of the present study is the cross-sectional nature of the data, which does not allow us to 
272 make causal interpretations. The relation between weight status and chronic bullying victimization

273 is dynamic. Actual and perceived weight can serve as both a cause and a consequence of being

274 bullied (Wilson et al. 2013). Therefore, longitudinal studies are needed to clarify the relationship.

275 Another limitation was that BMI calculations in our study were based on self-reported data from

the participants. Evidence supported the high correlation between self-reported and measured BMI in adolescents(Himes et al. 2005; Paxton et al. 2004). However, misclassification of some overweight and obese cases was likely (Elgar et al. 2005). Also, self-reported BMI overestimated the prevalence of underweight in adolescents(Yngve et al. 2008). Third, our study only investigated the general bullying in all forms and did not cover specific types of bullying such as physical, verbal, relational and cyberbullying. Compared with underweight adolescents, peers with overweight or obesity are targets of different kinds of bullying(Wang et al. 2010). Longitudinal studies with more comprehensive data on bullying and weight status are needed to investigate this

more closely. Fourth, some of the important confounders including race/ethnicity and child abuse

were not included in the analysis because using a secondary data, which could potentially confound the association of bullying victimization with perceived weight status and body self-image.

\section{Conclusions}

In conclusion, our findings have shown that both overweight and self-rated overweight relate to chronic bullying victimization in adolescents. Also, adolescents with underweight and perceived themselves as thin are both at higher risk of being chronically bullied than normal-weight peers.

Our study suggests that underweight adolescents need the same attention as their peers with overweight or obesity do in the fight against school bullying. 
293

294

295

296

297

298

299

300

301

302

303

304

305

306

307

308

309

310

311

312

313

314

315

316

317

318

319

320

321

322

323

324

325

326

\section{Acknowledgments:}

HBSC is an international study carried out in collaboration with WHO/EURO. The International

Coordinator of the 2009/10 survey was Prof. Candace Currie, University of St Andrews, UK and

the Data Bank Manager was Prof. Oddrun Samdal, University of Bergen, Norway. The 2009/10

survey was conducted by Principal Investigators in 39 countries/regions. For details, see

http://www.hbsc.org.

\section{References}

Anthony BJ, Wessler SL, and Sebian JK. 2010. Commentary: Guiding a Public Health Approach to Bullying. Journal of Pediatric Psychology 35:1113-1115. 10.1093/jpepsy/jsq083

Bacchini D, Licenziati MR, Affuso G, Garrasi A, Corciulo N, Driul D, Tanas R, Fiumani PM, Di Pietro E, Pesce S, Crino A, Maltoni G, Iughetti L, Sartorio A, Deiana M, Lombardi F, and Valerio G. 2017. The Interplay among BMI z-Score, Peer Victmization, and Self-Concept in Outpatient Children and Adolescents with Overweight or Obesity. Child Obes 13:242-249. 10.1089/chi.2016.0139

Bacchini D, Licenziati MR, Garrasi A, Corciulo N, Driul D, Tanas R, Fiumani PM, Di Pietro E, Pesce S, Crinò A, Maltoni G, Iughetti L, Sartorio A, Deiana M, Lombardi F, and Valerio G. 2015. Bullying and Victimization in Overweight and Obese Outpatient Children and Adolescents: An Italian Multicentric Study. PLoS ONE 10:e0142715. 10.1371/journal.pone.0142715

Bowes L, Maughan B, Ball H, Shakoor S, Ouellet-Morin I, Caspi A, Moffitt TE, and Arseneault L. 2013. Chronic bullying victimization across school transitions: The role of genetic and environmental influences. Development and psychopathology 25:10.1017/S0954579412001095. 10.1017/S0954579412001095

Chester KL, Callaghan M, Cosma A, Donnelly P, Craig W, Walsh S, and Molcho M. 2015. Cross-national time trends in bullying victimization in 33 countries among children aged 11, 13 and 15 from 2002 to 2010. European Journal of Public Health 25:61-64. 10.1093/eurpub/ckv029

Cole TJ, Bellizzi MC, Flegal KM, and Dietz WH. 2000. Establishing a standard definition for child overweight and obesity worldwide: international survey. Bmj 320:1240-1243.

Cole TJ, Flegal KM, Nicholls D, and Jackson AA. 2007. Body mass index cut offs to define thinness in children and adolescents: international survey. Bmj 335:194. 10.1136/bmj.39238.399444.55

Craig W, Harel-Fisch Y, Fogel-Grinvald H, Dostaler S, Hetland J, Simons-Morton B, Molcho M, de Mato MG, Overpeck M, Due P, Pickett W, Violence H, Injuries Prevention Focus G, and Group HBW. 2009. A crossnational profile of bullying and victimization among adolescents in 40 countries. Int J Public Health 54:216224. 10.1007/s00038-009-5413-9

Currie C, Molcho M, Boyce W, Holstein B, Torsheim T, and Richter M. 2008. Researching health inequalities in adolescents: The development of the Health Behaviour in School-Aged Children (HBSC) Family Affluence Scale. Social Science \& Medicine 66:1429-1436. http://dx.doi.org/10.1016/j.socscimed.2007.11.024 
Elgar FJ, Pfortner TK, Moor I, De Clercq B, Stevens GW, and Currie C. 2015. Socioeconomic inequalities in adolescent health 2002-2010: a time-series analysis of 34 countries participating in the Health Behaviour in School-aged Children study. Lancet 385:2088-2095. 10.1016/s0140-6736(14)61460-4

Elgar FJ, Roberts C, Tudor-Smith C, and Moore L. 2005. Validity of self-reported height and weight and predictors of bias in adolescents. $J$ Adolesc Health 37:371-375. 10.1016/j.jadohealth.2004.07.014

Fanti KA, and Henrich CC. 2015. Effects of Self-Esteem and Narcissism on Bullying and Victimization During Early Adolescence. The Journal of Early Adolescence 35:5-29. 10.1177/0272431613519498

Farmer VL, Williams SM, Mann JI, Schofield G, McPhee JC, and Taylor RW. 2017. Change of School Playground Environment on Bullying: A Randomized Controlled Trial. Pediatrics. 10.1542/peds.2016-3072

Fernandez S, and Pritchard M. 2012. Relationships between self-esteem, media influence and drive for thinness. Eating Behaviors 13:321-325. http://dx.doi.org/10.1016/j.eatbeh.2012.05.004

Gage NA, Prykanowski DA, and Larson A. 2014. School climate and bullying victimization: A latent class growth model analysis. School Psychology Quarterly 29:256-271. 10.1037/spq0000064

Haines J, Neumark-Sztainer D, Hannan PJ, van den Berg P, and Eisenberg ME. 2008. Longitudinal and secular trends in weight-related teasing during adolescence. Obesity (Silver Spring) 16 Suppl 2:S18-23. 10.1038/oby.2008.447

Himes JH, Hannan P, Wall M, and Neumark-Sztainer D. 2005. Factors associated with errors in self-reports of stature, weight, and body mass index in Minnesota adolescents. Ann Epidemiol 15:272-278. 10.1016/j.annepidem.2004.08.010

Jeong S, Kwak D-H, Moon B, and San Miguel C. 2013. Predicting School Bullying Victimization: Focusing on Individual and School Environmental/Security Factors. Journal of Criminology 2013:13. $10.1155 / 2013 / 401301$

Kochenderfer BJ, and Ladd GW. 1996. Peer victimization: cause or consequence of school maladjustment? Child Dev 67:1305-1317.

Ladd GW, Ettekal I, and Kochenderfer-Ladd B. 2017. Peer Victimization Trajectories From Kindergarten Through High School: Differential Pathways for Children's School Engagement and Achievement?

Latner JD, Ebneter DS, and O'Brien KS. 2012. Residual Obesity Stigma: An Experimental Investigation of Bias Against Obese and Lean Targets Differing in Weight-Loss History. Obesity 20:2035-2038. 10.1038/oby.2012.55

Lian Q, Zuo X, Mao Y, Luo S, Zhang S, Tu X, Lou C, and Zhou W. 2017. Anorexia nervosa, depression and suicidal thoughts among Chinese adolescents: a national school-based cross-sectional study. Environmental Health and Preventive Medicine 22:30. 10.1186/s12199-017-0639-2

Lumeng JC, Forrest P, Appugliese DP, Kaciroti N, Corwyn RF, and Bradley RH. 2010. Weight status as a predictor of being bullied in third through sixth grades. Pediatrics 125:e1301-1307. 10.1542/peds.2009-0774

Olweus D. 1994. Bullying at School: Basic Facts and Effects of a School Based Intervention Program. Journal of Child Psychology and Psychiatry 35:1171-1190. 10.1111/j.1469-7610.1994.tb01229.x

Olweus D. 2013. School bullying: development and some important challenges. Annu Rev Clin Psychol 9:751-780. 10.1146/annurev-clinpsy-050212-185516

Paxton RJ, Valois RF, and Drane JW. 2004. Correlates of body mass index, weight goals, and weight-management practices among adolescents. $J$ Sch Health 74:136-143.

Puhl RM, and King KM. 2013. Weight discrimination and bullying. Best Practice \& Research Clinical Endocrinology 
\& Metabolism 27:117-127. http://dx.doi.org/10.1016/j.beem.2012.12.002

Puhl RM, and Luedicke J. 2012. Weight-Based Victimization Among Adolescents in the School Setting: Emotional Reactions and Coping Behaviors. J Youth Adolesc 41:27-40. 10.1007/s10964-011-9713-z

Puhl RM, Luedicke J, and Heuer C. 2011. Weight-based victimization toward overweight adolescents: observations and reactions of peers. $J$ Sch Health 81:696-703. 10.1111/j.1746-1561.2011.00646.x

Ranta K, Kaltiala-Heino R, Pelkonen M, and Marttunen M. 2009. Associations between peer victimization, selfreported depression and social phobia among adolescents: the role of comorbidity. $J$ Adolesc 32:77-93. 10.1016/j.adolescence.2007.11.005

Reulbach U, Ladewig EL, Nixon E, O'Moore M, Williams J, and O'Dowd T. 2013. Weight, body image and bullying in 9-year-old children. Journal of Paediatrics and Child Health 49:E288-E293. 10.1111/jpc.12159

Rigby K, and Smith PK. 2011. Is school bullying really on the rise? Social Psychology of Education 14:441-455. 10.1007/s11218-011-9158-y

Shetgiri R. 2013. Bullying and Victimization Among Children. Advances in pediatrics 60:33-51. 10.1016/j.yapd.2013.04.004

Smith PK, Madsen KC, and Moody JC. 1999. What causes the age decline in reports of being bullied at school? Towards a developmental analysis of risks of being bullied. Educational Research 41:267-285. 10.1080/0013188990410303

Stapinski LA, Araya R, Heron J, Montgomery AA, and Stallard P. 2015. Peer victimization during adolescence: concurrent and prospective impact on symptoms of depression and anxiety. Anxiety Stress Coping 28:105120. 10.1080/10615806.2014.962023

Sutter C, Nishina A, and Adams RE. 2015. How you look versus how you feel: Associations between BMI z-score, body dissatisfaction, peer victimization, and self-worth for African American and white adolescents. Journal of Adolescence 43:20-28. https://doi.org/10.1016/j.adolescence.2015.05.002

Tippett N, and Wolke D. 2014. Socioeconomic status and bullying: a meta-analysis. Am J Public Health 104:e48-59. 10.2105/ajph.2014.301960

Wang J, Iannotti RJ, and Luk JW. 2010. Bullying Victimization Among Underweight and Overweight U.S. Youth: Differential Associations for Boys and Girls. Journal of Adolescent Health 47:99-101. https://doi.org/10.1016/j.jadohealth.2009.12.007

Wang J, Iannotti RJ, and Nansel TR. 2009. School bullying among adolescents in the United States: physical, verbal, relational, and cyber. $J$ Adolesc Health 45:368-375. 10.1016/j.jadohealth.2009.03.021

Wilson ML, Viswanathan B, Rousson V, and Bovet P. 2013. Weight Status, Body Image and Bullying among Adolescents in the Seychelles. International Journal of Environmental Research and Public Health 10:17631774. 10.3390/ijerph10051763

Yngve A, De Bourdeaudhuij I, Wolf A, Grjibovski A, Brug J, Due P, Ehrenblad B, Elmadfa I, Franchini B, Klepp K-I, Poortvliet E, Rasmussen M, Thorsdottir I, and Perez Rodrigo C. 2008. Differences in prevalence of overweight and stunting in 11-year olds across Europe: The Pro Children Study. European Journal of Public Health 18:126-130. 10.1093/eurpub/ckm099

Zequinão MA, de Medeiros P, Rosário HRVd, Pelegrini A, Lopes L, Pereira B, and Cardoso FL. 2017. Association between body dissatisfaction and bullying in children of socioeconomically vulnerable areas. Porto Biomedical Journal 2:260-264. https://doi.org/10.1016/j.pbj.2017.04.010 
Table $\mathbf{1}$ (on next page)

Description of study sample $(N=213,595)$ 


\begin{tabular}{ll}
\hline Characteristics & $\mathbf{n}(\mathbf{\%})$ \\
\hline Individual level & \\
Sex & \\
Male & $105,099(49.20)$ \\
Female & $108,496(50.80)$ \\
Age group (years) & \\
11 & $67,924(32.11)$ \\
13 & $71,975(34.02)$ \\
15 & $71,652(33.87)$ \\
Chronic bullying victimization & \\
No & $179,581(88.72)$ \\
Yes & $22,822(11.28)$ \\
Perceived weight status & \\
Underweight & $22,227(12.79)$ \\
Normal weight & $125,794(72.41)$ \\
Overweight & $21,176(12.19)$ \\
Obese & $4,528(2.61)$ \\
Perceived body-image & \\
Too thin & $30,580(14.57)$ \\
About right & $119,737(57.06)$ \\
A little bit fat & $52,157(24.85)$ \\
Too fat & $7,374(3.51)$ \\
Country level characteristics & $\mathbf{M e a n}(\mathbf{S D})$ \\
Mean income per person (GDP per capita in USD) & $35,052.34(21,331.34)$ \\
Countries & $31.94(4.70)$ \\
Schools & 39 \\
& 7,468 \\
\hline
\end{tabular}

2 
Table 2 (on next page)

The prevalence of chronic bullying victimization, by gender 
Table 2 The prevalence of chronic bullying victimization, by gender

\begin{tabular}{llll}
\hline & Total, $\mathbf{n}(\%)$ & Male, $\mathbf{n}(\%)$ & Female, $\mathbf{n}(\%)$ \\
\hline Age group(years) & $22,628(11.28)$ & $12,282(12.51)$ & $10,346(10.10)$ \\
11 & $8,515(13.25)$ & $4,506(14.37)$ & $4,009(12.18)$ \\
13 & $8,239(12.10)$ & $4,452(13.42)$ & $3,787(10.84)$ \\
15 & $5,874(8.61)$ & $3,324(9.88)$ & $2,550(7.37)$ \\
Perceived weight status & & & \\
Underweight & $2,333(11.12)$ & $1,035(13.34)$ & $1,298(9.81)$ \\
Normal weight & $11,852(9.90)$ & $6,475(10.95)$ & $5,377(8.87)$ \\
Overweight & $2,841(14.09)$ & $1,738(14.33)$ & $1,103(13.72)$ \\
Obese & $824(18.95)$ & $511(18.98)$ & $313(18.91)$ \\
Perceived body-image & & & \\
Too thin & $3,736(12.98)$ & $2,298(13.86)$ & $1,438(11.78)$ \\
About right & $10,380(9.13)$ & $6,063(10.29)$ & $4,317(7.88)$ \\
A little bit fat & $6,614(13.12)$ & $3,161(15.81)$ & $3,453(11.34)$ \\
Too fat & $1,790(25.02)$ & $692(29.57)$ & $1,098(22.81)$ \\
\hline
\end{tabular}

2 


\section{Table 3(on next page)}

The association between weight status and chronic bullying victimization, $\mathrm{OR}(95 \% \mathrm{Cl}, \mathrm{p}$ value) 
Table 3 The association between weight status and chronic bullying victimization, OR (95\%CI, $\mathrm{p}$ value)

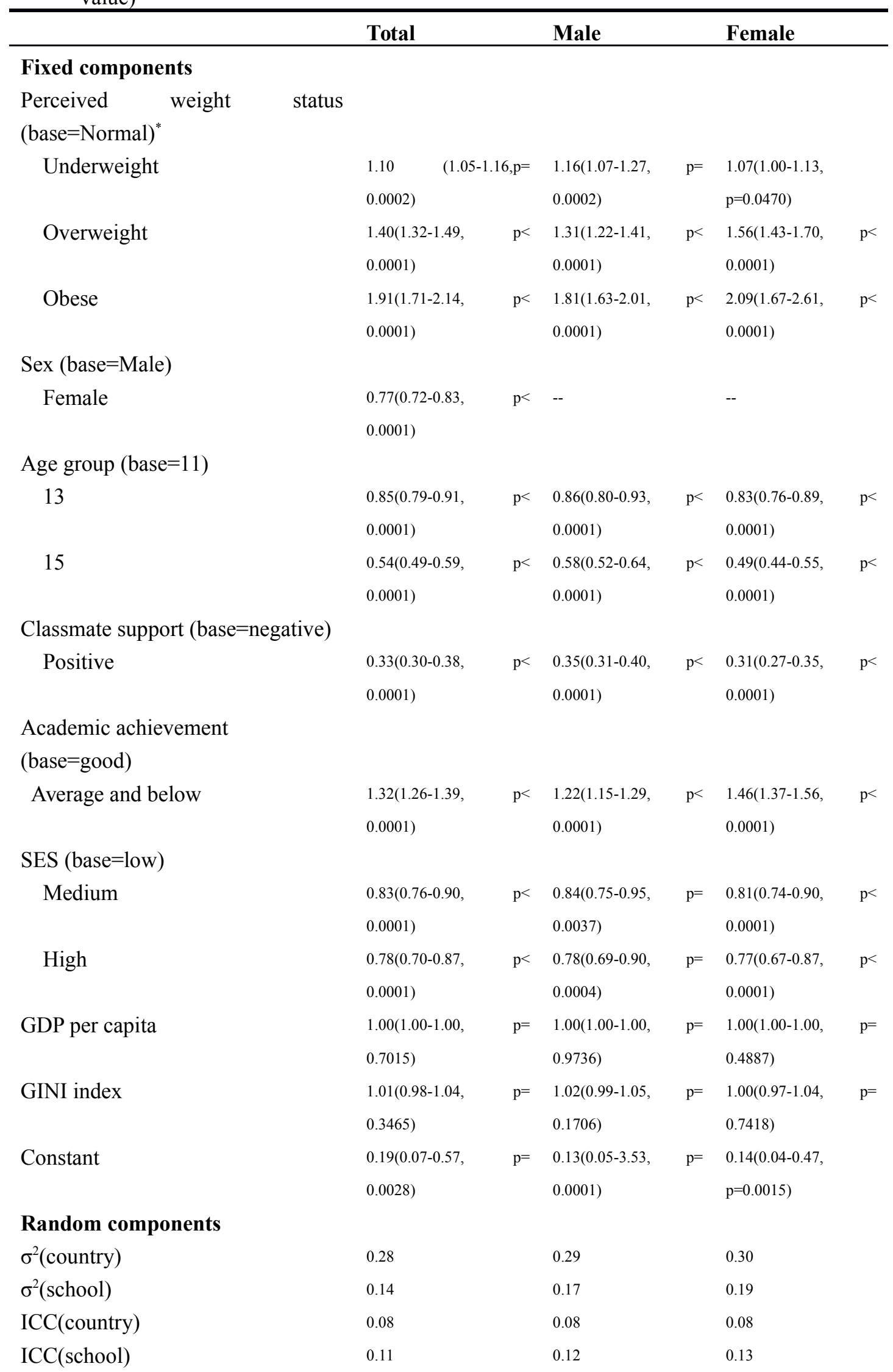


AIC\#

98295

52144

46118

BIC\#

98444

52273

46248

ICC $=$ Intraclass correlation. $\mathrm{AIC}=$ Akaike's information criterion. BIC $=$ Bayesian information criterion. \# Goodness-of-fit index.

* Odds ratio adjusted for sex, age group, classmate support, academic achievement, SES, GDP per capita and GINI index. 


\section{Table 4 (on next page)}

The association between body self-image and chronic bullying victimization, $\mathrm{OR}(95 \% \mathrm{Cl}$, $p$ value) 
Table 4 The association between body self-image and chronic bullying victimization, OR (95\%CI, $\mathrm{p}$ value)

\begin{tabular}{|c|c|c|c|c|c|c|}
\hline & Total & & Male & & Female & \\
\hline \multicolumn{7}{|l|}{ Fixed components } \\
\hline \multicolumn{7}{|l|}{ Perceived body-image } \\
\hline \multicolumn{7}{|l|}{$(\text { base }=\text { Normal })^{*}$} \\
\hline \multirow[t]{2}{*}{ Too thin } & 1.42(1.36-1.49, & $\mathrm{p}<$ & $1.39(1.31-1.47$ & $\mathrm{p}<$ & $1.47(1.38-1.57$ & $\mathrm{p}<$ \\
\hline & $0.0001)$ & & $0.0001)$ & & $0.0001)$ & \\
\hline \multirow[t]{2}{*}{ A little bit fat } & 1.54(1.48-1.61, & $\mathrm{p}<$ & $1.60(1.50-1.71$ & $\mathrm{p}<$ & $1.50(1.42-1.59$ & $\mathrm{p}<$ \\
\hline & $0.0001)$ & & $0.0001)$ & & $0.0001)$ & \\
\hline \multirow[t]{2}{*}{ Too fat } & $3.30(2.96-3.68$ & $\mathrm{p}<$ & $3.25(2.84-3.72$ & $\mathrm{p}<$ & $3.35(2.97-3.78$ & $\mathrm{p}<$ \\
\hline & $0.0001)$ & & $0.0001))$ & & $0.0001)$ & \\
\hline \multicolumn{7}{|l|}{$\operatorname{Sex}($ base=Male $)$} \\
\hline \multirow[t]{2}{*}{ Female } & $0.71(0.66-0.76$ & $\mathrm{p}<$ & -- & & -- & \\
\hline & $0.0001)$ & & & & & \\
\hline \multicolumn{7}{|c|}{ Age group (base = 11 years) } \\
\hline \multirow[t]{2}{*}{13 years } & $0.82(0.76-0.87$ & $\mathrm{p}<$ & $0.84(0.78-0.91$ & $\mathrm{p}<$ & $0.78(0.72-0.88$ & $\mathrm{p}<$ \\
\hline & $0.0001)$ & & $0.0001)$ & & $0.0001)$ & \\
\hline \multirow[t]{2}{*}{15 years } & $0.52(0.47-0.57$ & $\mathrm{p}<$ & $0.57(0.51-0.63$ & $\mathrm{p}<$ & $0.46(0.0 .41-0.52$ & $\mathrm{p}<$ \\
\hline & $0.0001)$ & & $0.0001)$ & & $0.0001)$ & \\
\hline \multicolumn{7}{|l|}{ Classmate support } \\
\hline \multicolumn{7}{|l|}{ (base $=$ negative) } \\
\hline \multirow[t]{2}{*}{ Positive } & $0.34(0.31-0.38$ & $\mathrm{p}<$ & $0.36(0.32-0.40$ & $\mathrm{p}<$ & $0.32(0.28-0.36$ & $\mathrm{p}<$ \\
\hline & $0.0001)$ & & $0.0001)$ & & $0.0001)$ & \\
\hline \multirow{2}{*}{\multicolumn{7}{|c|}{$\begin{array}{l}\text { Academic achievement } \\
(\text { base }=\text { good) }\end{array}$}} \\
\hline & & & & & & \\
\hline \multirow[t]{2}{*}{ Average and below } & 1.27(1.21-1.34, & $\mathrm{p}<$ & $1.21(1.15-1.28$ & $\mathrm{p}<$ & 1.35(1.26-1.43, & $\mathrm{p}<$ \\
\hline & $0.0001)$ & & $0.0001)$ & & $0.0001)$ & \\
\hline \multicolumn{7}{|l|}{ SES(base=low) } \\
\hline \multirow[t]{2}{*}{ Medium } & $0.84(0.78-0.91$ & $\mathrm{p}<$ & 0.87(0.77-0.98, & $\mathrm{p}=$ & $0.81(0.74-0.88$ & $\mathrm{p}<$ \\
\hline & $0.0001)$ & & $0.0255)$ & & $0.0001)$ & \\
\hline \multirow[t]{2}{*}{ High } & $0.79(0.72-0.87$ & $\mathrm{p}<$ & $0.81(0.71-0.83$ & $\mathrm{p}=$ & $0.76(0.68-0.84$ & $\mathrm{p}<$ \\
\hline & $0.0001)$ & & $0.0026)$ & & $0.0001)$ & \\
\hline \multirow[t]{2}{*}{ GDP per capita } & 1.00(1.00-1.00, & $\mathrm{p}=$ & $1.00(1.00-1.00$ & $\mathrm{p}=$ & $1.00(1.00-1.00$ & $\mathrm{p}=$ \\
\hline & $0.8763)$ & & $0.8987)$ & & $0.6554)$ & \\
\hline \multirow[t]{2}{*}{ GINI index } & 1.02(0.99-1.05, & $\mathrm{p}=$ & $1.02(1.00-1.05$ & $\mathrm{p}=$ & 1.01(0.98-1.05, & $\mathrm{p}=$ \\
\hline & $0.1914)$ & & $0.0914)$ & & $0.4553)$ & \\
\hline \multirow[t]{2}{*}{ Constant } & $0.17(0.06-0.51$ & $\mathrm{p}=$ & $0.10(0.04-0.28$ & $\mathrm{p}<$ & $0.11(0.03-0.34$ & $\mathrm{p}=$ \\
\hline & $0.0015)$ & & $0.0001)$ & & $0.0004)$ & \\
\hline \multicolumn{7}{|l|}{ Random components } \\
\hline$\sigma^{2}($ country $)$ & 0.26 & & 0.26 & & 0.28 & \\
\hline$\sigma^{2}(\mathrm{school})$ & 0.14 & & 0.16 & & 0.19 & \\
\hline ICC(country) & 0.07 & & 0.07 & & 0.07 & \\
\hline
\end{tabular}




$\begin{array}{llll}\text { ICC(school) } & 0.11 & 0.11 & 0.13 \\ \text { AIC\# } & 119053 & 62574 & 56454 \\ \text { BIC\# } & 119206 & 62706 & 56587\end{array}$

$\mathrm{ICC}=$ Intraclass correlation. $\mathrm{AIC}=$ Akaike's information criterion. $\mathrm{BIC}=$ Bayesian information criterion. \# Goodness-of-fit index.

* Odds ratio adjusted for sex, age group, classmate support, academic achievement, SES, GDP per capita and GINI index. 
Figure 1

The prevalence of chronic bullying victimization by age, weight status and body selfimage $(n=213,595)$
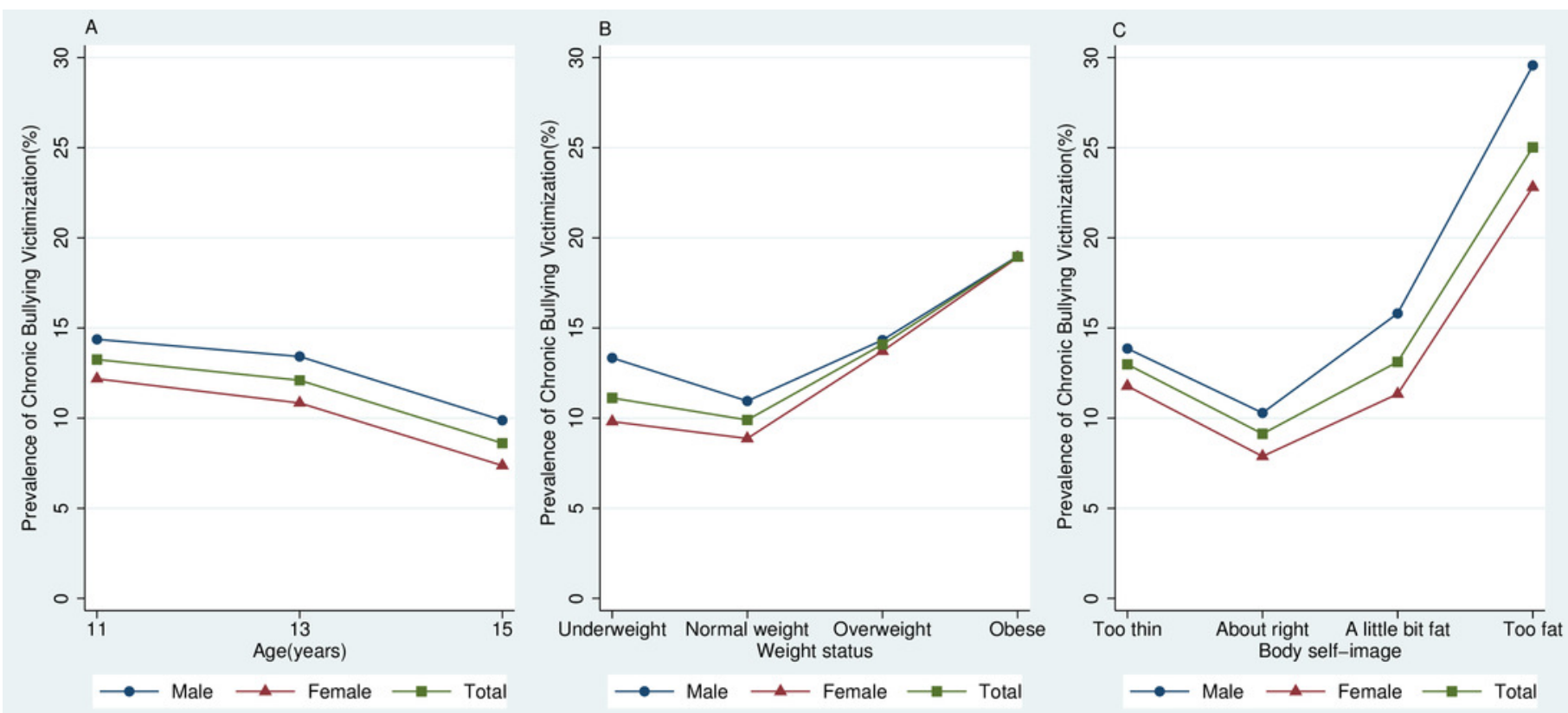
Figure 2

\section{The estimated probabilities for weight status and body self-image}
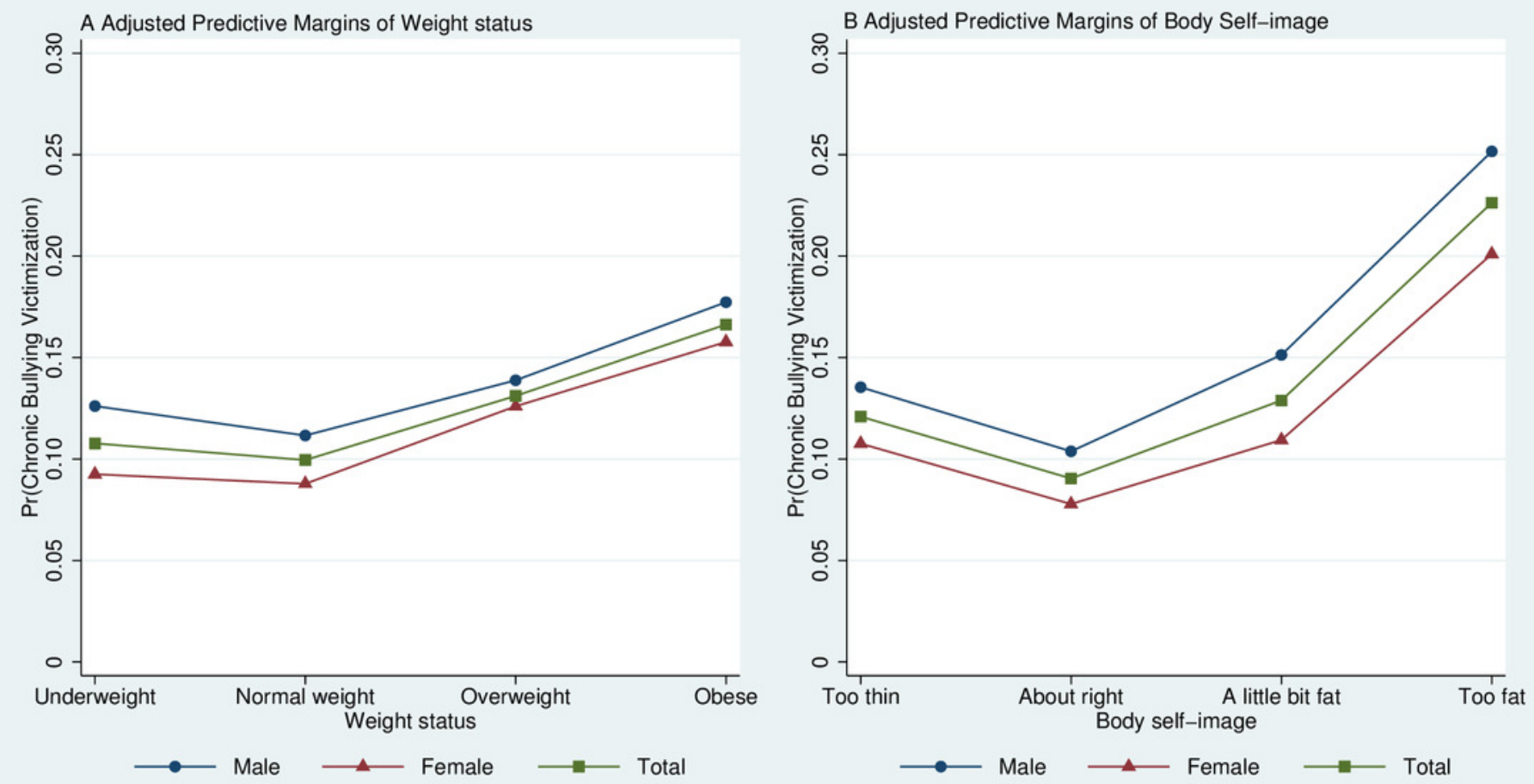